\title{
Leader Scholar Communities: Supporting EdD Students' Dissertation in Practice Efforts
}

\author{
Ray Buss, PhD \\ Mary Fulton Teachers College \\ Arizona State University \\ ray.buss@asu.edu \\ James G. Allen, EdD \\ College of Education \\ Northern Kentucky University \\ allenj4@nku.edu
}

\begin{abstract}
In this essay, we discuss Leader Scholar Communities (LSCs), which have proven to be helpful in supporting students' dissertation in practice (DiP) efforts in several CPED-guided programs. We have organized this essay around four important topics including (a) describing a theoretical framework that serves as the foundation for LSCs, (b) providing a rationale for using LSCs, (c) illustrating how LSCs have been implemented to support students' DiP efforts in our EdD programs, and (d) exploring the benefits and limitations of LSCs. We have also presented research information about graduates' perceptions of LSCs. We concluded by presenting some questions others might wish to contemplate as they consider the use of LSCs to support their students' DiP efforts.
\end{abstract}

\section{KEYWORDS}

reducing doctoral attrition; leader scholar communities; dissertation in practice; communities of practice

In this essay, we described Leader Scholar Communities (LSCs) and how they have been used to support EdD students as they developed, implemented, and completed their Dissertations in Practice (DiP) in two CPED-guided programs. Briefly, LSCs were groups of students and faculty members who worked together during the last two years of the program to ensure students made timely progress with respect to developing the DiP proposal, implementing the DiP including collecting and analyzing the data, and writing the final version of the DiP. We have organized this essay around four important topics including (a) describing a theoretical framework that served as the foundation for LSCs, (b) providing a rationale for using LSCs, (c) illustrating how LSCs have been implemented to support students' DiP efforts in our EdD programs, and (d) exploring the benefits and limitations of LSCs.

\section{THEORETICAL FRAMEWORK- COMMUNITIES OF PRACTICE}

Etienne Wenger's (1998; Wenger et al., 2002) communities of practice (CoP) framework has served as the theoretical framework for LSCs. Wenger et al. (2002) suggested CoP were defined by three elements: "a domain of knowledge, which defines a set of issues; a community of people who care about this domain; and the shared practice that they are developing to be effective in the domain" (p. 27, italics in original). We have described these concepts more fully in the next sections.
Wenger et al. (2002) suggested, "The domain of a CoP creates a common ground and sense of common identity .... The domain inspires members to contribute and participate, guides their learning, and gives meaning to their actions" (p. 27-28, italics in original). For example, in the current context, the domain for the LSC were tasks related to the $\mathrm{DiP}$ including designing it, writing a proposal, implementing an intervention and collecting data, analyzing data, and writing and defending the final version of the DiP. In addition, the domain included the logistical matters associated with the DiP such as selecting and engaging committee members, completing the comprehensive examination, holding the proposal and dissertation defenses, and so on.

With respect to community, Wenger et al. (2002) claimed, "The community creates the social fabric of learning. A strong community fosters interactions and relationships based on mutual respect and trust" (p. 28). Thus, the community was a collaborative entity where participants willingly interacted with one another and developed relationships that facilitated and supported the DiP process. Specifically, students shared information and ideas about their problems of practice, research methods, and other DiP processes; and capitalized on opportunities in which they supported each other academically and emotionally.

"The practice is a set of frameworks, ideas, tools, information, styles, language, stories, and documents that community members share. .... the domain denotes the topic... [whereas] the practice is the specific knowledge the community develops, shares, and 
maintains" (Wenger et al., 2002, p. 29, italics in original). Thus, the practice component of the CoP consisted of the various ideas, tools information, and so on needed to complete the DiP, which the community shared formally, as they met together in the LSC and informally, as they connected with one another outside of the organized sessions. In the current context, practice included knowledge about research design and implementation, data collection and analyses, logistical information and guidelines for the DiP, and so on.

In Wenger's (1998) earlier work on CoP, he focused on how participation in a CoP influenced identity. For example, in the current context, students' participation in an LSC aided in molding their identities as graduate student, scholarly practitioner, and educational researching professional, an educational researcher focused on solving problems in their workplace settings (Bourner, Bowden, \& Laing, 2001) among other identities. Because Wenger viewed identity as something that was constantly being (re)negotiated within a CoP or in other settings, we have viewed the LSC as playing a fundamental role in shaping EdD students' identity and behavior as scholarly practitioners during the dissertation process and afterward.

Thus, Wenger's (1998; Wenger et al., 2002) CoP framework guided implementation of LSCs. Moreover, the CoP framework was a natural extension of the cohort group process, which students had experienced as they participated in the first year of their EdD programs.

\section{The Problem of Completing the EdD}

Attrition has been a crucial concern in doctoral programs (Lovitts, 2001; Walker et al., 2008). For many years, attrition from PhD programs has been around $50 \%$ or slightly higher (Bowen \& Rudenstine, 1992; Cassuto, 2013; Council of Graduate Schools, 2008; Lovitts, 2001). Attrition costs manifested themselves in two ways. Of course, there were financial costs to the individual and to the institution. Nevertheless, the more noteworthy cost has been to the individual. As Lovitts (2001) maintained, "The most important reason to be concerned about graduate student attrition is that it can ruin individuals' lives" (p. 6).

Various factors such as program area, funding, gender, ethnicity, and integration into the program have affected attrition. With regard to these factors, Ali and Kohun $(2006,2007)$ and Lovitts (2001) found the extent to which students were integrated with peers and faculty members into a program played a critical role in retention and completion. Quite naturally, concerns about attrition led us to consider the following questions as we designed and implemented EdD programs at our two institutions. 'How can we best support students as they develop, implement, and complete their DiP?' and 'How can we work effectively with EdD students to avoid having allbut-dissertation (ABD) participants in our programs?' We anticipated these questions were also of primary concern to faculty members at other CPED-guided Colleges and Schools of Education. Evidence from the October 2017 CPED Convening supported that conjecture as over 35 of us considered these matters during a Learning Exchange on Leader Scholar Communities (Buss \& Allen, 2017). Because of that substantial interest among CPED members, we decided to write this essay on our use of Leader Scholar Communities (LSCs), logistical matters with respect to LSCs, and the benefits and 'costs' of their use.

\section{Rationale for Leader Scholar Communities}

First, we wanted to avoid the problem of social isolation, which has plagued many students who have completed coursework and who were then 'on their own' to complete the dissertation. Students typically perceived they had strong support during the coursework phase of their doctoral study. By comparison, students frequently have felt isolated and on their own during the dissertation phase of their programs, which typically has been much less structured than coursework (Ali \& Kohun, 2006, 2007; Lovitts, 2001; Walker et al., 2008). To combat isolation during the dissertation stage of study, Ali and Kohun (2007) proposed using three strategies that included (a) providing structure for the dissertation work, (b) employing a collaborative approach to the dissertation, and (c) engaging in faceto-face communication. As noted below in the next section and in the discussions of the Leader Scholar Communities in Action, we have provided greater structure, capitalized on collaborative efforts, and afforded opportunities for students to connect regularly with other students, faculty members, and their programs.

Second, our efforts in developing the LSCs have also been guided by the CPED framework including the third CPED Guiding Principle-building partnerships; the fifth-integrating practical and research knowledge; and the sixth - emphasizing use of professional knowledge and practice, which have been discussed more fully below; and the CPED Program Design Concept of signature pedagogy. Notably, the LSC has been and continues to be a signature pedagogy in our programs. Shulman (2005) suggested signature pedagogies were disciplinary approaches such as cases in law or rounds in medicine, which were then directly applicable in professional practice. In the current context, signature pedagogies included action research, LSCs, and so on used in doctoral programs that were also appropriate for use in workplace situations after doctoral study. Specifically, LSCs as used in our programs represented the kind of professional communities within which our students have been/will be required to work as they influence their workplace settings. Moreover, use of LSCs has been consistent with several CPED Principles. With respect to the third CPED Principle, students used collaboration and communication skills to build partnerships, which were effectively used during the program, the LSC, and which will be necessary in their professional practices afterward. Moreover, LSC meetings afforded opportunities for members to develop professional knowledge that integrated practical and research knowledge, the fifth CPED Principle, as they pondered theories and shared practical, professional knowledge with one another during the LSC meetings and used this information as they developed, implemented, and wrote their DiPs. Finally, LSCs supported students' efforts to effect transformations in their workplaces as they considered and combined professional knowledge and practice, the sixth CPED Principle, while they designed and implemented their DiPs.

\section{LEADER SCHOLAR COMMUNITIES IN ACTION}

\section{LSCs Defined in Detail}

Recall earlier we stated LSCs were groups of students and faculty members who worked together during the last two years of the program to ensure students made timely progress with respect to developing the DiP proposal, implementing the DiP including collecting and analyzing the data, and writing the final version of the DiP. In the Mary Lou Fulton Teachers College at Arizona State 
University, LSCs typically have been composed of six to seven students and one faculty member. The faculty member served as chair of all the DiPs for these students and facilitated their DiP efforts. Students came with their own problems of practice (PoPs) from their workplace settings; thus, faculty members viewed students as experts with regard to their settings, their PoPs, and the potential intervention they considered with respect to their PoP. Notably, faculty members and peers have honored this knowledge in the LSCs. The faculty member has contributed methodological, research, and writing expertise to enhance and support students' DiP efforts and mentored students throughout the process.

In the College of Education and Human Services at Northern Kentucky University, LSCs have been organized a bit differently. Two faculty members worked as a team in co-leading and coadvising an LSC with five to six students whom we called learning associates. This term denoted the democratic context in which our learners and program faculty came together-mutually teaching and learning together. Much like Arizona State University, faculty members served as experts in action research, scholarly literature and writing, and the learning associates applied organizational and leadership expertise to their problems of practice as the DiPs were developed and implemented.

\section{Logistics and LSCs}

With respect to logistical aspects of LSCs, we have provided information about two matters-forming LSCs and scheduling of LSC meetings. First, in terms of forming LSCs at Arizona State University, we have created diverse LSCs by mixing students from K-12, higher education, and other disciplinary areas. We have found these groups to be complementary in terms of interest and needs, which students have appreciated as well. We have also formed LSCs to ensure students with various writing abilities have been distributed across the LSCs. The LSCs have been constituted at the end of the first year of the program when students were moving into DiP proposal development and writing

At Northern Kentucky University, LSCs were formed at the beginning of the second year of the three-year program. Since the beginning of our program 10 years ago, we have formed a variety of LSCs from transdisciplinary groups-a mix of higher education leaders, PK-12 school administrators, healthcare educators, and so on-to homogenous groups based on similar job roles or problems of practice. Prior to the formation of LSCs, we sought input from learning associates and faculty members to determine the best approach to forming LSCs for each particular cohort.

Second, at Arizona State University, LSCs usually have met every other week for about three months to support students' initial efforts, then once a month for the last two months of the first semester of their second year. During these last two months, students also met individually with their LSC chairs to advance their work. During the second semester, typically three group meetings were held to ensure continuity with respect to sustaining the sense of community established in the LSCs. These meetings made students aware of the logistics and assignments relevant to the semester. Subsequently, we held individual meetings to meet the needs of students, which culminated in their oral comprehensive examinations and defenses of their DiP proposals. During the third semester of the LSC, students were collecting their DiP data and initiating analysis of the data, so two group meetings were held to re-establish the supportive aspects of the LSC and then individual meetings were held with students to meet their needs. In the final semester when students completed writing and defending their DiPs, we followed the same process.

At Northern Kentucky University, similar logistical processes have been employed with some slight variations. LSCs were scheduled to meet approximately once a month, typically during the regularly scheduled once-a-month weekend class meetings within the second year of the program. In this way, learning associates were already on campus, which eased the scheduling challenges for busy practitioners. Between the monthly meetings, learning associates often scheduled face-to-face and in a few instances virtual writing sessions with each other to develop components of their DiPs in preparation for their next LSC meeting. In the third year, after completion of course work and comprehensive examinations, LSC meetings and collaborative writing sessions kept the DiP front and center in a mutually supportive environment during what has traditionally been an unstructured time in doctoral work. We met with learning associates on an as-needed basis in individual meetings.

\section{Content}

At Arizona State University, content of the LSC meetings has been quite diverse and included, for example, updates by students on their progress with respect to DiP efforts. Additionally, LSC meeting content has included logistical matters such as recruitment of second and third committee members, filing appropriate forms, timelines for submission of writing, and so on. With respect to substantive content, LSC meetings have included discussions of theories, research methods, data analysis procedures, and other content appropriate for students who were developing, implementing, analyzing, and writing their DiPs.

Faculty members embedded similar content within the Northern Kentucky University program. In conjunction with LSC meetings during the spring of year two, learning associates took a three-credithour 'dissertation seminar' course designed to provide additional content and support as they fully developed their dissertation proposals. Requirements of this course included the development of the research methodology for the DiP, research ethics, time management, and navigating the dissertation project. LSC faculty members regularly communicated with the instructor of this course to connect fully the learning experiences in the course to the efforts being conducted in LSCs. After the dissertation seminar, LSCs continued to meet and provide on-going support and feedback on dissertation proposals. As learning associates transitioned to conducting their action research for the DiP, LSCs continued to meet once a month and mutually supported one another between meetings by continuing to schedule regular writing sessions.

\section{General Tasks}

General tasks conducted in the LSCs included (a) reviewing and completing program requirements for the $\mathrm{DiP},(\mathrm{b})$ reviewing and completing Graduate School matters, (c) scheduling defenses, and (d) IRB processes. For example, students completed appropriate paper work such as an electronic program of study, and paperwork for DiP proposal defenses, DiP final defenses, IRB materials, and so on. 


\section{Tasks Related to Completing the DiP}

We included a separate section on tasks related to completing the DiP to illustrate how we have used LSCs to assist students in their DiP efforts. For example, at Northern Kentucky University, the initial task procedures included a topic approval process where the student consulted with and then presented an action research topic to the LSC faculty members for approval. As the precursor to the dissertation proposal, learning associates constructed a brief preliminary proposal based on their responses to the following questions:

1. Who are you? A brief personal biography is appropriate.

2. What is the work place, agency, or group the research would involve? What is your role in that organization?

3. What is your proposed topic? Why is this a significant problem/issue in the workplace, agency, or group, which involve them in your research?

4. How is your proposed topic related to educational leadership?

5. How is your proposed topic related to action research?

LSC faculty members reviewed and approved learning associates' topics prior to allowing learning associates move forward with developing a DiP proposal.
Following the approval of the topic, at Northern Kentucky University, in consultation with the two faculty members of the LSC, each learning associate nominated and selected a third committee member who brought an outside perspective to the DiP research. The third member was typically a practitioner with a terminal degree from outside of the program who was familiar with the context and/or setting of the DiP. By comparison, at Arizona State University students and their chair collaborated to select, recruit, and secure second and third committee members. The second committee member was a university faculty member who had expertise in the content of the dissertation, whereas the third committee member who also had a terminal degree was from the community, was familiar with the context or setting of the dissertation, and brought a practitioner's perspective to the dissertation committee.

As students moved forward in developing their DiP proposals, they constructed the proposals in sections, by chapter, and received feedback from their peers, detailed feedback from their chairs, and from committee members. Students, chairs, and committee members engaged in a similar process for the development of the final written DiP. In Table 1, details have been provided about the sequencing of the tasks involved in Step three of the DiP process as well as the concomitant collaborative, review and feedback procedures afforded by the LSC.

Table 1. Steps in the Dissertation in Practice and How Leader Scholar Communities Support Those Steps

\begin{tabular}{|c|c|}
\hline Steps in the DiP Process & Specific Actions Related to DiP Conducted in the LSC \\
\hline $\begin{array}{l}\text { 1. Action Research Topic Approval (Northern Kentucky University } \\
\text { only) }\end{array}$ & $\begin{array}{l}\text { - Learning associate submits topic for approval } \\
\text { to faculty members }\end{array}$ \\
\hline 2. Selecting External Committee Members & $\begin{array}{l}\text { Discuss process and review forms including } \\
\text { template letter }\end{array}$ \\
\hline \multirow{6}{*}{$\begin{array}{l}\text { 3. Developing the DiP Proposal } \\
\text { - } \quad \text { Develop/revise research questions to guide DiP } \\
\text { - } \quad \text { Develop/write Context for the Project and Purpose of the } \\
\text { Action Research DiP Proposal } \\
\text { - Develop/write Theoretical Perspectives and Research Guiding } \\
\text { the Project of the DiP Proposal } \\
\text { - Develop/write Method of the DiP Proposal }\end{array}$} & - $\quad$ Read/discuss previous 'model' DiPs \\
\hline & - $\quad$ Share and then refine research questions \\
\hline & based on peer and then LSC chair feedback \\
\hline & $\begin{array}{l}\text { revise DiP proposal components based on } \\
\text { peer and then LSC chair feedback }\end{array}$ \\
\hline & $\begin{array}{l}\text { - Group sessions and later individual sessions } \\
\text { afforded students with optimal opportunities } \\
\text { for interaction and feedback }\end{array}$ \\
\hline & - $\quad$ Committee feedback \\
\hline \multirow[t]{2}{*}{$\begin{array}{l}\text { 4. Conducting the DiP Proposal Defense and the Comprehensive } \\
\text { Examination }\end{array}$} & $\begin{array}{l}\text { - Preparation of DiP proposal defense with } \\
\text { presentation to LSC peers who provide } \\
\text { feedback, then proposal defense }\end{array}$ \\
\hline & - $\quad$ Chair and committee feedback \\
\hline 5. Implementing the DiP Study & $\begin{array}{l}\text { Group sessions to share progress, } \\
\text { challenges, and resolutions with peer and } \\
\text { LSC chair feedback }\end{array}$ \\
\hline 6. Analyzing Quantitative and Qualitative Data & $\begin{array}{l}\text { - Group and then individual sessions with the } \\
\text { LSC chair as appropriate }\end{array}$ \\
\hline \multirow{3}{*}{$\begin{array}{l}\text { 7. Completing Culminating Work } \\
\text { - } \quad \text { Writing of Findings/Results of the DiP } \\
\text { - } \quad \text { Writing of Discussion of the DiP }\end{array}$} & - $\quad$ By specified deadline dates, share and then \\
\hline & \\
\hline & - $\quad$ Committee feedback \\
\hline \multirow[t]{2}{*}{ 8. Defending the Final DiP } & $\begin{array}{l}\text { Preparation of DiP defense with presentation } \\
\text { to LSC peers who provide feedback prior to } \\
\text { actual defense }\end{array}$ \\
\hline & - $\quad$ Chair \& committee feedback \\
\hline
\end{tabular}


First, to obtain a general understanding of developing the DiP proposal, students in the LSC have read and discussed 'model' DiPs written by graduates of the program. As part of developing the DiP proposal, students developed or revised their research questions that guided the DiP by sharing and then refining their research questions based on peer and then LSC chair feedback. Next, students tackled the task of developing and writing about the context for the project and purpose of the action research DiP. This document was due by a specified date, which allowed for peer review and comment and subsequent revision prior to submission to the LSC chair who provided thorough edits and comments. Students followed these same processes of peer review and comment, revision, submission to the LSC chair, and receipt of the chair's edits and comments for the Theoretical Perspectives and Research Guiding the Project, Chapter 2, and the Method, Chapter 3, of the DiP proposal. In Table 1, we have provided additional details about conducting the DiP proposal defense and comprehensive examination, implementing the DiP, and so on as part of the DiP process along with the respective, concurrent actions taken in the LSC to support the DiP process.

\section{A Note About LSCs for Online Students}

Faculty members had concerns about whether the program could effectively implement LSCs online as we moved to adding online students to our program at Arizona State University. We have now implemented the LSCs with online students for the past twoand-one-half years and have found the process to be similar to those procedures used in the face-to-face setting. After trying several different video conferencing tools, we have found Zoom to be effective for these online LSC meetings. The cost of a license for the year was quite reasonable. With respect to outcomes, the results of these online LSCs have been on par with those attained in the previous face-to-face version of the program (Craig Mertler, personal communication, Nov. 15, 2017). In fact, some students in the online LSCs met before or after the scheduled online meeting with their chairs to initiate or continue the discussion of content, logistical issues, and so on that were to be covered/were covered in the LSC meeting (Craig Mertler, personal communication, Nov. 15, 2017). These actions, both formal with the chair and informal with peers, attested to the power of the CoP framework in fostering a community among online LSC participants.

\section{Benefits of LSCs}

LSCs produced several important benefits. First, using LSCs has provided for high completion rates. For example, at Arizona State University over $88 \%$ of those admitted to our program have completed it in three years and $93 \%$ in four years. In fact, the largest attrition has occurred in the first two semesters of the program prior to when students became members of an LSC. At Northern Kentucky University, the program attained similar results with $70 \%$ of students graduating in three years and $91 \%$ in four years. Moreover, using LSCs has minimized the number of ABD students in the programs, which was a concern of all program faculty members. These completion rates were well above those typical of most doctoral programs, which have shown completion rates at about $50 \%$ (Bowen \& Rudenstine, 1992; Council of Graduate Schools, 2008; Lovitts, 2001).

Second, by using LSCs during the DiP phase of the programs, we have minimized or eliminated isolation, which Ali and Kohun
$(2006,2007)$ claimed was a major issue with respect to students completing programs. Recall, these authors suggested providing structure, affording collaborative efforts, and offering face-to-face involvement were critical to combating isolation. In this respect, LSCs provided opportunities to effectively deal with all three of these matters. Specifically. LSCs have provided greater structure for carrying out the various efforts that are required to design, conduct, gather and analyze data, and complete the DiP. Group and individual meetings, specific content for the DiP and its processes, and clear tasks have been components of the LSCs that established greater structure for students working on their DiP. Additionally, LSCs fostered collaboration and maximized student-to-facultymember cooperation. Similarly, the LSCs provided affordances for face-to-face engagement with faculty members and student peers that facilitated the conduct of the DiP and its associated processes.

Third, LSCs provided a variety of benefits to students. We asked recent graduates at Arizona State University about their perceptions of LSCs using a semi-structured interview. Examples of questions were, "How has your LSC affected you," "What were the functions of your LSC," "What were the benefits of participating in your LSC," and "How could the LSC be strengthened?"

Results indicated recent graduates viewed LSCs as being beneficial. They described LSCs as being helpful in several ways by (a) providing a sounding board, a place for sharing ideas and obtaining feedback, (b) serving as an accountability group, and (c) offering academic and emotional support. Note: all names are pseudonyms. Graduates appreciated the LSC as a sounding board. Kim claimed, "It [LSC] provided friendships that made it easy to ask questions. And it alleviated some stress." In addition, Alexa valued the reviews by peers when she said, "[there were] so many opportunities to have some other people looking at my work."

In terms of sharing ideas, Caroline appreciated this aspect of the LSC when she said, "to meet and talk through things with other people because you live so much or your dissertation inside your own head. The ability to get feedback and a different perspective was really helpful." Kim described sharing ideas as an important function of the LSC when she said, "We got together to discuss and kind of say out loud what our thought process was. So, we presented ... our research design ... our literature ... and our intervention." Another Sylvia noted the LSC afforded support "by just being there to bounce ideas off of .... I also felt there was a peer there to help you with some revision or reviewing your writing if needed." Later, Sylvia added, "I thought [what] was valuable was being able to present ideas to other people." Alexa noted, "it was really helpful to have a smaller group to be able to throw ideas around with. ... we would present information to each other ... and then ... critique each other."

Other responses reflected the notion that LSCs offered a way to foster accountability for their work. For example, Holly mentioned, "I think more than anything accountability ... having the accountability of times on the calendar with people I trusted and cared about ... and having that time together ... [and] with goals was really helpful and motivating." Linda described the helpfulness of the LSC in the following way, "I think it helped me finish on time. ....I think without the LSC, I could see where people would get off track ... or get confused or frustrated. ... It kept us focused." Sylvia added the LSC served "to just kind of keep me on track and keep me accountable ... Making sure l'm getting things done." 
With respect to academic and emotional support, graduates offered many comments. For example, Holly stated, "And the support was I think more emotional than anything. They were great academic supports, but really it was a personal support of 'you can do it." Linda described how the LSC members came together to provide support when she said, "we started to lean on each other for support." Caroline described how informal support in the LSC was important to her when she stated, "The formal meetings were great, but for those of us who lived ... [closer] together, we would meet [between LSC meetings] to ... talk about where our projects were, so the informal aspects of the LSC were really helpful." Sylvia said, "I think regular contact after the formal coursework was completed was important ... [it created] that feeling of going back to class and keeping your focus on school." When describing others in her LSC, Alexa said, "they were going through a similar process ... So, it was kind of comforting to know that you weren't the only one." Later, Alexa noted, "they [LSC members] were always really encouraging. ... we wanted to see each other succeed ... so, [we did] whatever we could do to reach out and help each other."

Moreover, Holly said, "We were in constant communication .... they [LSC members] were my number one supporters and critical friends so we could bounce idea off of and hold each other accountable." Similarly, Linda indicated the LSC was "a great support mechanism. .... the group of students that were with me formed a little network and a close community where I felt I could reach out to them." Additionally, Caroline suggested, "The benefits were really getting external feedback, working together on everyone's projects, and getting the experience of defending or working through problems together."

Graduates made several suggestions about strengthening the LSCs. Several graduates indicated grouping students differently in LSCs might be beneficial to students. For example, Alexa indicated most peers in her LSC were in PK-12, but there were some students from higher education. At both institutions, students came from a wide range of professions including PK-12, higher education, nonprofit organizations, nursing, and so on. Thus, more homogenous grouping by educational context might have been more helpful. Sylvia offered there should be "more consistency across LSCs" because expectations varied by LSC chair. Kim suggested faculty members should consider geographic location more fully so that it would be easier for members to gather informally (although others did as noted previously).

\section{Implications from LSC Data}

Taken together, it is clear graduates believe they benefit from participating in LSCs (see also Amrein-Beardsley et al., 2012; Olson \& Clark, 2009). Respondents indicate LSCs serve as sounding boards, function as accountability groups, offer feedback, and provide academic and emotional support as they engage in their DiP efforts. Respondents are advocates for LSCs and claim they are beneficial. As Lovitts (2001) notes, academic and social integration into a 'community' are critical for student success in doctoral programs.

Moreover, LSCs are aligned with several of the CPED principles. Thus, LSCs reinforce and afford opportunities directly benefitting students during the program and afterward. For example, the third CPED Principle stipulates that students employ collaboration and communication skills to build partnerships. LSCs foster these skills during the program for ongoing use afterward as graduates continue to develop their professional practices in their workplace settings. Additionally, LSC meetings provide opportunities for students to integrate practical and research knowledge as they share professional practice knowledge and consider theoretical perspectives, the fifth CPED Principle. With respect to the sixth CPED Principle, LSCs provide situations in which students consider how they might create transformative changes in their workplace settings as they consider and combine professional knowledge and practice.

\section{CRITIQUE OF LSCS}

First, faculty members must evaluate the use of LSCs relative to other advising and mentoring programs during the DiP phase of study in an EdD program. For example, what is the cost/benefit ratio for LSCs as compared to some other program that may already be implemented? In an evaluation of competing programs, faculty members must consider issues such as completion rates, faculty members' time, degree of complexity of LSCs as compared to the other approach(es), and so on.

Second, if LSCs are being used in a program, careful consideration must be given to the ways in which LSCs are formed and the benefits and costs of creating specific types of LSCs. For example, can greater benefits be achieved by creating homogeneous LSC groups that include only students from PK-12 in separate LSCs and students from higher education settings in other LSCs? Alternatively, could greater benefits be attained by grouping students into the same LSCs who are working on similar problems? By comparison, would heterogeneous LSCs be useful? Thus, the costs (and benefits) of forming LSCs in specific ways should be carefully considered to maximize outcomes for students in the LSC. In the interviews, graduates note some of these concerns about optimizing benefits for students in LSC formation.

\section{FUTURE RESEARCH AND PRACTICE}

In some final thoughts, we consider two important matters. The first deals with research about LSCs. The second matter is concerned with using LSCs in practice.

With respect to research, there are several aspects of LSCs that warrant additional inquiry. For example, what are the effects of heterogeneous as compared to homogeneous grouping by background (PK-12 vs. higher education vs. other)? Can enhanced outcomes be attained when students are grouped into LSCs based on the same or similar topic(s)? In another line of inquiry, researchers might consider further, what are the benefits of LSCs?

With respect to practice and based on the information presented, there appears to be much that recommends the use of LSCs as a means to support EdD students' DiP efforts. For those considering the use of LSCs, the following questions appear to be quite relevant. Do the benefits of using LSCs including increasing graduation rates (eliminating $A B D s$ ); completing programs in timely ways; overcoming isolation; providing academic and emotional support; and offering affordances to meet several CPED Guiding principles outweigh the financial, psychological, and personal costs? Is financial support or some 'work around' available in the College? Is administrative support accessible? Is faculty member support attainable? If so, then use of LSCs may be a productive way to 


\section{support EdD students' DiP efforts as we have found at our} institutions.

\section{REFERENCES}

Ali, A., \& Kohun, F. (2006). Dealing with isolation feelings at IS doctoral programs. International Journal of Doctoral Studies, 1, 21-33. Retrieved from http://ijds.org/Volume1/IJDSv1p021-033Ali13.pdf

Ali, A, \& Kohun, F. (2007). Dealing with social isolation to minimize doctoral attrition-A four stage framework. International Journal of Doctoral Studies, 2. 33-49. Retrieved from http://www.ijds.org/Volume2/IJDSv2p033-049Ali28.pdf

Amrein-Beardsley, A., Zambo, D., Moore, D. W., Buss, R. R., Perry, N. J., Painter, S. R.,

Carlson, D. L., Foulger, T. S., Olson, K., \& Puckett, K. S. (2012). Graduates respond to an innovative educational doctorate program. Journal of Research on

Leadership Education, 7(1), 98-122. Retrieved from https://doi.org/10.1177/1942775112440630Bourner, T., Bowden, R., \& Laing, S. (2001). Professional doctorates in England. Studies in Higher Education, 26(1), 65-83.

Bowen, W. G., \& Rudenstine, N. L, (1992). In pursuit of the PhD. Princeton University Press.

Buss, R., R., \& Allen, J. (2017, October). Leader scholar communities support students' dissertation in practice efforts. Learning Exchange presented at the October Convening of the Carnegie Project on the Education Doctorate (CPED), Oakland, CA.

Cassuto, L. (2013, July). Ph.D. attrition: How much is too much? The Chronicle of Higher Education. Retrieved from https://www.chronicle.com/article/PhD-Attrition-How-Much-Is/140045

Council of Graduate Schools. (2008). Ph.D. completion and attrition: Analysis of baseline program data from the Ph.D. completion project. Author.

Lovitts, B. E. (2001). Leaving the ivory tower: The causes and consequences of departure from doctoral study. Rowman \& Littlefield.

Olson, K., \& Clark, C. M. (2009). A signature pedagogy in education: The leader-scholar community. Educational Researcher, 38, 216-221.
Shulman, L. S. (2005). Signature pedagogies in the professions. Daedalus, 134(3), 52-59.

Walker, G. E., Golde, C. M., Jones, L., Bueschel, A. C., \& Hutchings, P. (2008). The formation of scholars: Rethinking doctoral education for the twentyfirst century. Jossey-Bass.

Wenger, E. (1998). Communities of practice: Learning, meaning, and identity. Cambridge University Press.

Wenger, E., McDermott, R., \& Snyder, W. M. (2002). Cultivating communities of practice. Harvard Business School Press. 